\title{
Endoscopic removal of laser-cut covered self-expandable metallic biliary stents: A report of six cases
}

\author{
YUKI TANISAKA, SHOMEI RYOZAWA, MASANORI KOBAYASHI, MAIKO HARADA, TSUTOMU KOBATAKE, \\ KUMIKO OMIYA, HIROTOSHI IWANO, SHIN ARAI, KOUICHI NONAKA and YUMI MASHIMO
}

Department of Gastroenterology, Saitama Medical University International Medical Center, Hidaka, Saitama 350-1298, Japan

Received August 18, 2017; Accepted November 22, 2017

DOI: $10.3892 / \mathrm{mco} .2017 .1515$

\begin{abstract}
Covered self-expandable metallic stents (CSEMS) may provide palliative drainage for unresectable distal malignant biliary strictures. Laser-cut CSEMS allows easy positioning due to its characteristic of minimal stent shortening. Endoscopic stent removal is sometimes recommended for recurrent biliary obstruction (RBO). However, there are no previous reports of endoscopic removal of laser-cut CSEMS. The current study presents data from 6 patients who were placed a laser-cut CSEMS for unresectable distal malignant biliary strictures, and later endoscopic stent removal was attempted for RBO at the present institute. The duration of stent placement, the procedural success rate, the procedural duration, and accidental complications were evaluated. The mean duration of stent placement was $156 \pm 37.9$ days (range, 117-205). The procedural success rate was $100 \%$. The mean procedural duration was $11.8 \pm 7.5 \mathrm{~min}$ (range, 5-24). No complications were reported. Laser-cut CSEMS were safely removed from all patients. The present case report is the first to demonstrate that Endoscopic stent removal of laser-cut CSEMS was safely performed.
\end{abstract}

\section{Introduction}

Endoscopic biliary stenting is an established technique used to treat obstructive jaundice and cholangitis. Self-expandable metallic stents (SEMS) are now used more often than plastic stents (PS) for palliative drainage for unresectable distal malignant biliary strictures because of their longer duration of stent patency (1-5). Isayama et al compared covered SEMS (CSEMS) and uncovered SEMS (USEMS) in a randomized study and reported that CSEMS had a longer duration of patency because they prevented tumor

Correspondence to: Dr Shomei Ryozawa, Department of Gastroenterology, Saitama Medical University International Medical Center, 1397-1, Yamane, Hidaka, Saitama 350-1298, Japan

E-mail: ryozawa@saitama-med.ac.jp

Key words: unresectable distal malignant biliary strictures, endoscopic stent removal, drainage, laser-cut, covered self-expandable metallic stent ingrowth (6). The X-Suit NIR ${ }^{\circledR}$ Covered Biliary Metallic Stent (Olympus Medical Systems, Tokyo, Japan) is a laser-cut CSEMS used as the first-choice device for treating unresectable distal malignant biliary strictures at the Department of Gastroenterology, Saitama Medical University International Medical Center because it allows easy positioning due to its characteristic of having minimal stent shortening (Fig. 1).

After SEMS placement, the presence of recurrent biliary obstruction (RBO) can affect the duration of stent patency. Considering recent advancements in chemotherapy, re-intervention for RBO will be crucial. Different treatment approaches are used depending on the cause of RBO. Replacing the old SEMS with a new SEMS is the most common re-intervention approach for RBO used in recent studies (7-10). However, the CSEMS removal reported to date involved only braided stents. Endoscopic removal of laser-cut CSEMS has not been reported. Thus, we herein report the efficacy and safety of endoscopically removing laser-cut CSEMS.

\section{Case report}

Patients. The X-Suit NIR ${ }^{\circledR}$ Covered Biliary Metallic Stents, which are a type of laser-cut CSEMSs, were placed in 64 consecutive patients with unresectable distal malignant biliary strictures at Saitama Medical University International Medical Center between October 2014 and December 2016. We performed endoscopic sphincterotomy (EST) before stent placement and placed laser-cut CSEMSs across the papilla. RBO was reported in 7 patients $(10.9 \%)$ after stenting. With the exception of the 1 patient with complete stent migration. Complete migration refers to CSEMS in the gastrointestinal tract or outside the body.

Stent removal. Our indications for CSEMS removal are as follow: i) Stent occlusion because of overgrowth or sludge within the stent; ii) distal migration with impaction against the duodenal wall opposite the papilla. Distal migration has the risk of not only associated occlusion but also formation of erosions and ulcers from mechanical irritation, and serious gastrointestinal tract perforation.

Patients with poor general health conditions or terminal malignancy who are expected to survive for $>2$ months are not 
indicated to undergo stent removal. They are appropriate for stent cleaning or plastic stent insertion.

A therapeutic duodenoscope (TJF-260 V and JF-260V, Olympus Medical Systems, Tokyo, Japan) was used for endoscopic stent removal. Snare forceps (SD-5L-1) or V-shaped grasping forceps (FG-44NR-1) (Olympus Medical Systems) were used to hold the stent. The stent held with the forceps was gradually pulled towards the papilla by repeated pushing and clockwise torsion of the endoscope. The proximal end of the visible part of stent was held again, and the entire stent was eventually pulled out into the duodenum. Subsequently, the stent and the endoscope were carefully removed together from the patient's body while under endoscopy and fluoroscopy guidance to avoid damage to the surrounding organs. All patients received information on the procedure and provided consent in advance to receive the treatment. This study was conducted in compliance with the Declaration of Helsinki and the Ethical Guidelines for Medical and Health Research Involving Human Subjects. This study was approved by the Institutional Review Board of Saitama Medical University International Medical Center (approval no. 16-293).

The duration of stent placement (from placement to endoscopic removal), procedural success rate, procedural duration, and the occurrence of accidental complications were evaluated.

\section{Results}

Endoscopic stent removal was performed in 6 patients with RBO. The male-to-female ratio was $2: 4$. The median age was 73.5 years (range, 39-83 years). The underlying disorder was pancreatic cancer in 3 patients and distal biliary cancer in 3 patients. The cause of RBO was stent occlusion with sludge in 5 patients and partial distal stent migration in 1 patient. Two patients received chemotherapy after the initial stenting (Table I).

The mean duration of stent placement (from placement to endoscopic removal) was 156 \pm 37.9 days (range, 117-205 days) in the patients who underwent stent removal. The procedural success rate was $100 \%(6 / 6)$. The mean procedural duration was $11.8 \mathrm{~min}$ (range, 5-24 $\mathrm{min}$ ). Snare forceps were used in 5 patients while both snare forceps and grasping forceps were used in 1 patient for stent removal. The procedure was lengthy because the stent was carefully removed to avoid stent fracture. No complications, such as gastrointestinal tract damage, occurred during stent removal. A SEMS was placed in all patients after the removal of the old stent (Table II). The outcomes of the 64 patients who underwent X-Suit NIR ${ }^{\circledR}$ Covered Biliary Metallic Stent placement are shown (Fig. 2). We show a representative case (Case 5) of a patient who underwent safe occluded stent removal with careful endoscopic procedures using snare forceps. This patient had a new CSEMS placed following stent occlusion with sludge that occurred at 201 days after the initial stenting as shown in (Fig. 3).

\section{Discussion}

With the recent advances in chemotherapy, patients may survive for a long time after SEMS placement. Therefore, the importance of re-intervention for RBO is increasing. Tumor ingrowth/mucosal hyperplasia, tumor overgrowth, sludge
Table I. Characteristics of patients who needed stent removal.

Characteristic Laser-cut CSEMS

Number of patients 6

Age, years

Median (range)

Sex

Male/female

$2(33.3 \%) / 4(66.7 \%)$

Primary disease

Pancreatic cancer

$3(50 \%)$

Bile duct cancer

$3(50 \%)$

Clinical stage (UICC)

Stage III

Stage IV

Chemotherapy

Recurrent biliary obstruction

Occlusion (Sludge)

Distal migration

$1(16.7 \%)$

Data shown as number (percentage) unless otherwise specified.

\section{A}

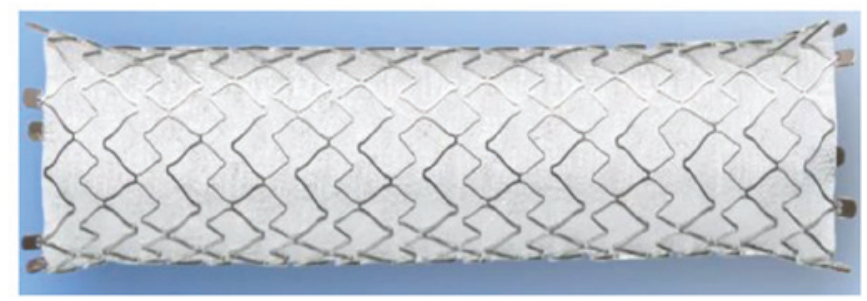

B

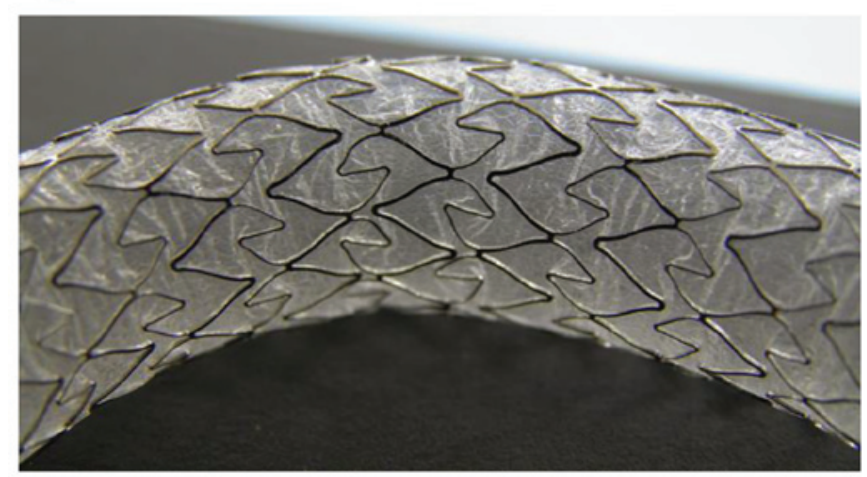

Figure 1. (A and B) The X-Suit NIR ${ }^{\circledR}$ Covered Biliary Metallic Stent (Olympus Medical Systems, Tokyo, Japan).

with/without stones, hemobilia, food impaction, and bile duct kinking as well as partial migration of the SEMS are listed as possible causes of RBO in the 2014 Tokyo criteria (11). The usefulness of CSEMS for preventing ingrowth in distal malignant biliary strictures has also been reported $(6,12)$. Braided CSEMSs like the Niti-S stents (TaeWoong Medical Co., Seoul, Korea) are feasible and effective for maliganct 
Table II. Outcome of stent removal.

\begin{tabular}{|c|c|c|c|c|c|}
\hline Case & Disease & Patency (d) & Procedure time (min) & Outcome & Additional procedure \\
\hline \multicolumn{6}{|c|}{ Occlusion (Sludge) } \\
\hline 1 & Bile duct ca. & 117 & 18 & Success & New SEMS \\
\hline 2 & Bile duct ca. & 150 & 24 & Success & New SEMS \\
\hline 3 & Pancreatic ca. & 129 & 5 & Success & New SEMS \\
\hline 4 & Bile duct ca. & 205 & 6 & Success & New SEMS \\
\hline 5 & Pancreatic ca. & 201 & 10 & Success & New SEMS \\
\hline \multicolumn{6}{|c|}{ Distal migration } \\
\hline 6 & Pancreatic ca. & 134 & 8 & Success & New SEMS \\
\hline
\end{tabular}

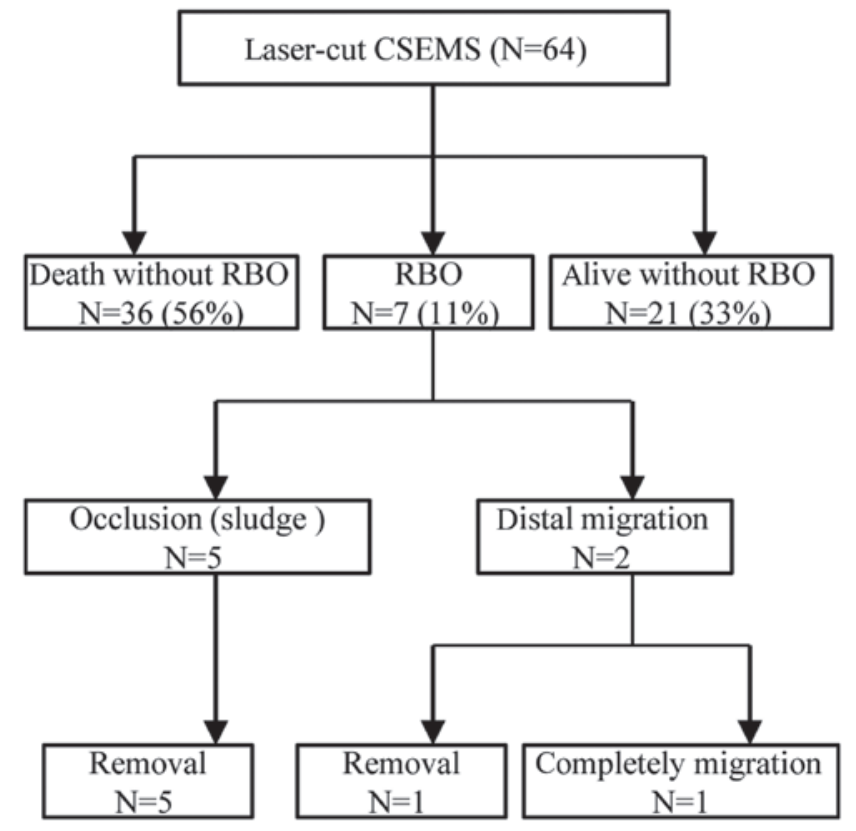

Figure 2. Outcomes of patients receiving laser-cut covered self-expandable metallic stent (CSEMS) placement.

biliary obstruction. Other investigators have reported that stent removal is relatively sinple $(8,10)$. However, braided CSEMSs are sometimes difficult to place in the appropriate position because they have much shortening function. Thus, the positioning of braided CSEMS must be decided considering shortening. On the other hand, laser-cut CSEMSs have limited shortening function. Thus, the appropriate position can be decided relatively easy.

Re-intervention approaches for RBO include stent cleaning with a balloon catheter and stent-in-stent placement. Togawa et al compared the re-intervention approaches used in 74 patients with CSEMS failure and reported short-term stent patency ( $<2$ months) for changing the old stent to a PS, stent-in-stent placement of a PS, and stent cleaning. The researchers recommend changing the old stent to a new CSEMS or stent-in-stent placement of a CSEMS (13). Bleeding of the orifice of the papilla can occur at stent removal. Thus, we need to remove the CSEMS gradually and carefully. When CSEMSs are placed for a long period, the covering membrane can break, which can causes tumor ingrowth. As pulling the CSEMS forcibly can damage the bile duct mucosa, the mobility of the CSEMS should be checked before removal.

According to a recent report, the success rate of SEMS removal ranges between $0-100 \%$ for USEMSs and 77.8-92.9\% for CSEMSs. A new SEMS was placed after old stent removal in 58.8-96.6\% of patients from whom a SEMS was removed (Table III) (7-10). USEMSs are more difficult to remove because the metallic stent becomes implanted in the tissue due to ingrowth. To our knowledge, removal of laser-cut USEMS has failed in all patients reported to date. Familiari et al explained this finding by the fact that braided-mesh SEMSs are resistant to longitudinal traction because of the crisscross mesh structure and are thus easy to remove, while laser-cut SEMSs which have a zigzag design with no crossing struts in the mesh are not resistant to longitudinal traction and easily tear on removal (8).

Removal of laser-cut CSEMS has not been previously reported. We successfully removed X-Suit NIR $^{\circledR}$ Covered Biliary Metallic Stents, which are a type of laser-cut CSEMS, under endoscopic guidance in $6 / 6$ patients. The reason for the successful removal of laser-cut SEMSs may be that the stents were covered with a double-layer of silicone and polyurethane, which makes the stent more resistant to longitudinal traction than laser-cut USEMSs are and which results in less ingrowth. Braided CSEMSs have a crisscross mesh structure. Since the entire stent shrinks and straightens once held by snare forceps, it is easy to pull into the forceps channel of the endoscope and remove. In contrast, laser-cut CSEMSs have no crisscross mesh structure and may be torn when pulled longitudinally. Thus, we must pull laser-cut CSEMSs gradually and carefully. Furthermore, laser-cut CSEMSs do not straighten when held by snare forceps. Thus, they can not be pulled into the working channel of the endoscope. Once the laser-cut CSEMS is pulled into the duodenum, the stent and the endoscope can carefully removed together from the patient's body under endoscopy and fluoroscopy guidance to avoid damage to the surrounding organs.

In conclusion, the X-Suit NIR $^{\circledR}$ Covered Biliary Metallic Stents were safely removed from all patients. Further accumulation of patient data will be necessary since the follow-up duration after CSEMS placement was relatively short and a small number of patients were evaluated. 
Table III. Review of stent removal.

\begin{tabular}{|c|c|c|c|c|c|}
\hline Authors & & MS & $\begin{array}{l}\text { Success rate } \\
\text { success/total } \\
\text { number }(\%)\end{array}$ & $\begin{array}{c}\text { Rate of new SEMS } \\
\text { success/total } \\
\text { number }(\%)\end{array}$ & (Refs.) \\
\hline \multicolumn{6}{|l|}{ Kahaleh et al } \\
\hline & USEMS & Braided & 4/4 (100) & & (7) \\
\hline & CSEMS & Braided & 13/14 (92.9) & & \\
\hline & Total & & 17/18 (94.4) & $10 / 17(58.8)$ & \\
\hline \multicolumn{6}{|l|}{ Familiari et al } \\
\hline & USEMS & Braided & $5 / 10(50)$ & & \\
\hline & & Laser-cut & $0 / 3(0)$ & & (8) \\
\hline & CSEMS & Braided & $24 / 26(92.3)$ & & \\
\hline & Total & & $29 / 39(74.4)$ & $28 / 29(96.6)$ & \\
\hline \multicolumn{6}{|l|}{ Shin et al } \\
\hline & USEMS & Braided & $0 / 5(0)$ & & \\
\hline & & Laser-cut & $0 / 3(0)$ & & (9) \\
\hline & CSEMS & Braided & $19 / 22(86.4)$ & & \\
\hline & Total & & $19 / 30(63.3)$ & $17 / 19(89.5)$ & \\
\hline \multicolumn{6}{|l|}{ Ishii et al } \\
\hline & USEMS & Braided & $0 / 1(0)$ & & (10) \\
\hline & CSEMS & Braided & $14 / 18(77.8)$ & & \\
\hline & Total & & $14 / 19(73.7)$ & $12 / 14(85.7)$ & \\
\hline Current study & CSEMS & Laser-cut & $6 / 6(100)$ & $6 / 6(100)$ & \\
\hline
\end{tabular}
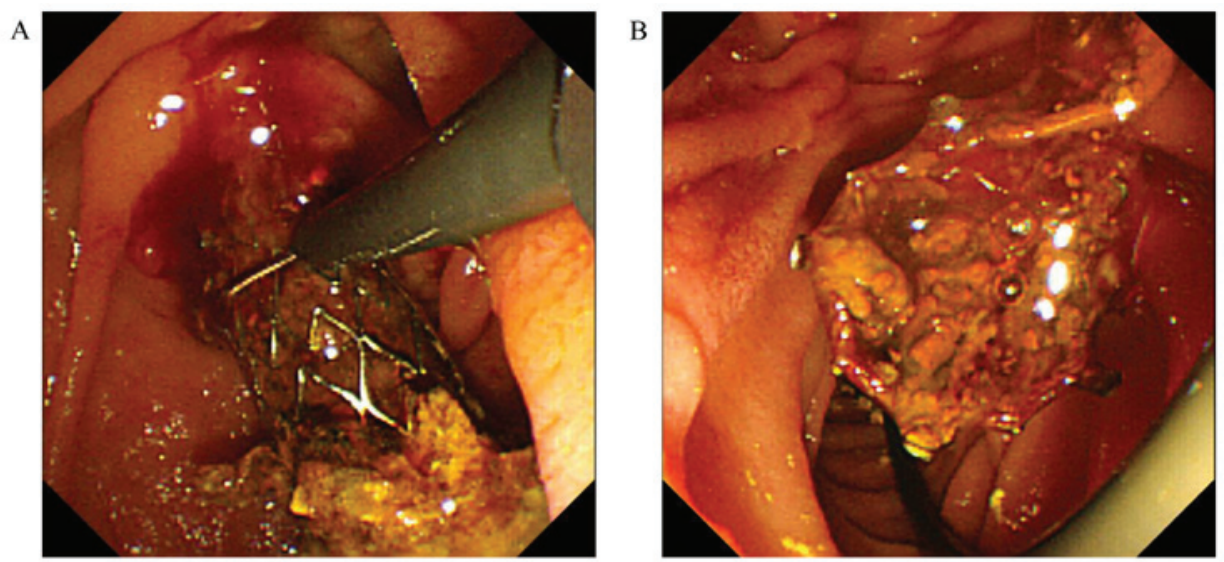

$\mathrm{C}$
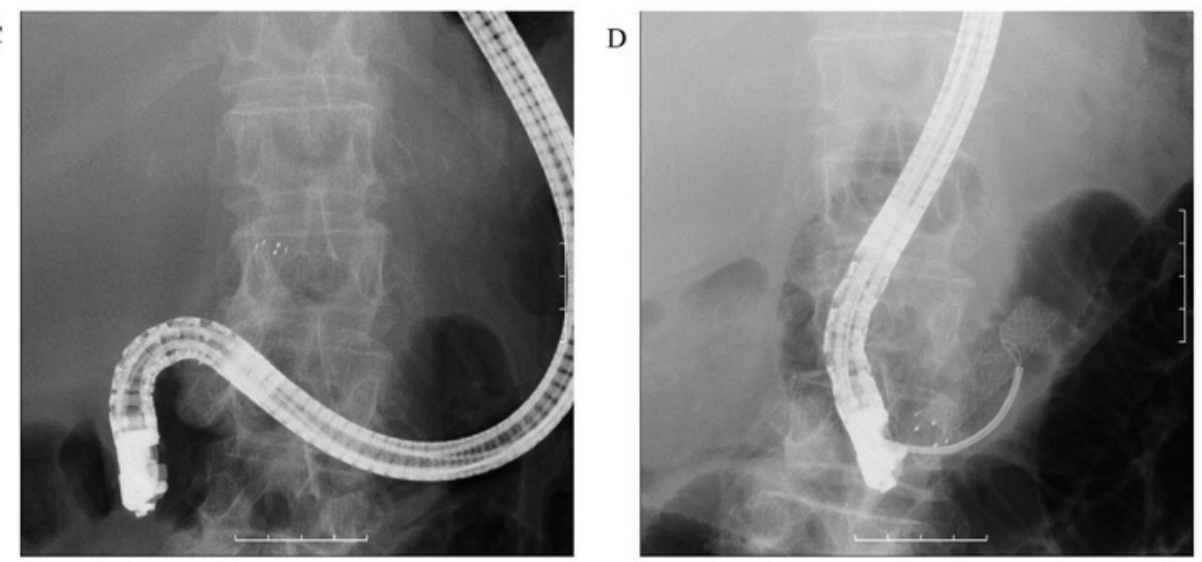

Figure 3. (A-D) A case of stent occlusion with sludge. The stent held with the snare forceps was gradually pulled towards the papilla by repeated pushing and clockwise torsion of the endoscope. The proximal end of the visible part of the stent was held again, and the entire stent was eventually pulled out into the duodenum. 


\section{References}

1. Davids PH, Groen AK, Rauws EA, Tytgat GN and Huibregtse K: Randomised trial of self-expanding metal stents versus polyethylene stents for distal malignant biliary obstruction. Lancet 340: 1488-1492, 1992.

2. Prat F, Chapat O, Ducot B, Ponchon T, Pelletier G, Fritsch J, Choury AD and Buffet C: A randomized trial of endoscopic drainage methods for inoperable malignant strictures of the common bile duct. Gastrointest Endosc 47: 1-7, 1998.

3. Kaassis M, Boyer J, Dumas R, Ponchon T, Coumaros D, Delcenserie R, Canard JM, Fritsch J, Rey JF and Burtin P: Plastic or metal stents for malignant stricture of the common bile duct? Results of a randomized prospective study. Gastrointest Endosc 57: 178-182, 2003.

4. Moss AC, Morris E, Leyden J and MacMathuna P: Do the benefits of metal stents justify the costs? A systematic review and meta-analysis of trials comparing endoscopic stents for malignant biliary obstruction. Eur J Gastroenterol Hepatol 19: 1119-1124, 2007.

5. Isayama H, Yasuda I, Ryozawa S, Maguchi H, Igarashi $\mathrm{Y}$, Matsuyama Y, Katanuma A, Hasebe O, Irisawa A, Itoi T, et al: Results of a Japanese multicenter, randomized trial of endoscopic stenting for non-resectable pancreatic head cancer (JM-test) Covered wallstent versus doublelayer stent. Dig Endosc 23: 310-315, 2011.

6. Isayama H, Komatsu Y, Tsujino T, Sasahira N, Hirano K, Toda N, Nakai Y, Yamamoto N, Tada M, Yoshida H, et al: A prospective randomised study of 'covered' versus 'uncovered' diamond stents for the management of distal malignant biliary obstruction. Gut 53: 729-734, 2004.

7. Kahaleh M, Tokar J, Le T and Yeaton P: Removal of self-expandable metallic Wallstents. Gastrointest Endosc 60 640-644, 2004.
8. Familiari P, Bulajic M, Mutignani M, Lee LS, Spera G, Spada C, Tringali A and Costamagna G: Endoscopic removal of malfunctioning biliary self-expandable metallic stents. Gastrointest Endose 62: 903-910, 2005.

9. Shin HP, Kim MH, Jung SW, Kim JC, Choi EK, Han J, Lee SS, Seo DW and Lee SK: Endoscopic removal of biliary self-expandable metallic stents: A prospective study. Endoscopy 38: 1250-1255, 2006

10. Ishii K, Itoi $\mathrm{T}$, Sofuni A, Itokawa $\mathrm{F}$, Tsuchiya $\mathrm{T}$, Kurihara $\mathrm{T}$, Tsuji S, Ikeuchi N, Umeda J, Moriyasu F and Tsuchida A: Endoscopic removal and trimming of distal self-expandable metallic biliary stents. World J Gastroenterol 17: 2652-2657, 2011.

11. Isayama H, Hamada T, Yasuda I, Itoi T, Ryozawa S, Nakai Y, Kogure H and Koike K: TOKYO criteria 2014 for transpapillary biliary stenting. Dig Endosc 27: 259-264, 2015.

12. Kitano M, Yamashita Y, Tanaka K, Konishi H, Yazumi S, Nakai Y, Nishiyama O, Uehara H, Mitoro A, Sanuki T, et al: Covered self-expandable metal stents with an anti-migration system improve patency duration without increased complications compared with uncovered stents for distal biliary obstruction caused by pancreatic carcinoma: A randomized multicenter trial. Am J Gastroenterol 108: 1713-1722, 2013.

13. Togawa O, Isayama H, Tsujino T, Nakai Y, Kogure H, Hamada T, Sasaki T, Yashima Y, Yagioka H, Arizumi T, et al: Management of dysfunctional covered self-expandable metallic stents in patients with malignant distal biliary obstruction. J Gastroenterol 48: $1300-1307,2013$

(i) This work is licensed under a Creative Commons Attribution-NonCommercial-NoDerivatives 4.0 International (CC BY-NC-ND 4.0) License. 